\title{
LA NUEVA EMPRESA
}

\author{
Prof. JORGE ENRIQUE MARC
}

\begin{abstract}
SUMARIO
I Introducción. a) Generalidades. b) La empresa precapitalista.

II Concepción de la empresa. a) Introducción. b) Concepto económico de la empresa. c) Concepto jurídico.

III La nueva empresa. a) La empresa eje del problema social. b) La nueva concepción de la empresa.

IV Los elementos de la empresa. a) Los elementos humanos de la empresa. b) Distintos regimenes de relaciones: $10^{\circ}$ El régimen salarial, y $2 .^{\circ}$ El régimen de la sociedad.

V La participación activa de los trabajadores en la empresa. a) Enquadramiento.

b) Participación en sus distintas formas: $1 .^{\circ}$ - participación en los benefícios. $2 .^{\circ}$ - participación en la dirección. $3 .^{\circ}$ - participación en la propiedad.

VI Conclusiones
\end{abstract}

1

\section{INTRODUCCIÓN}

\section{a) Generalidades}

Pareciera - prima facie - que el estudio de la Empresa nada tiene que ver con el Derecho del Trabajo y de la Seguridad Social. puesto que su organización se rige, hasta la fecha, en todos los paises, por disposiciones del Derecho Comercial, alcanzando singular importancia en el campo de la Economía.

La Empresa solo tendría, entonces, relevancia dentro del campo del Derecho Laboral, como sujeto de las relaciones tanto individuales - contrato individual de trabajo -, como colectivas - convenio colectivo de trabajo.

Sin embargo, como señala Pozzo (1), en los últimos se viene desenvolviendo un concepto distinto, que si bien no ha penetrado

1) POZZO, JUAN D. - Manual de Derecho del Trabajo - t. 1..$^{\circ}$ pg. 152 - Ed. 1961. 
totalmente, está alcanzando honda repercusión dentro de esta rama del Derecho.

Porque como vengo insistiendo, desde hace años, se está perfilando la transformación de la empresa, "de una comunidad de intereses en una comunidad de trabajo", de acuerdo a la acertada expresión tanto de Pio XII como de Juan XXIII.

Esta transformación conceptual se opera, no solo en el plano económico, sino, sobre todo, en la base misma de la institución, lo que ha hecho decir a George Rippert (3), que marcará "la decadencia del régimen capitalista", y, consecuentemente, la instauración de una nueva época, distinta desde el punto de vista de su organización social, política y económica".

La empresa empieza a ser considerada, señala Paul Durand (4), desde un punto de vista prevalentemente social, como una institución, conjunto de elementos humanos, porque los organismos no existan sinó en el pensamiento de los hombres que los constituyen.

Quiere decir, entonces, que, desde este punto de vista, de este nuevo punto de vista, la empresa debe ser considerada como "una sociedad de hombres, destinada a desarrollar su personalidad con el fin inmediało de mejorar la producción, pero, incuestionablemente, con el fín último, fundamental, de buscar el bien común de la sociedad" nacional e internacional.

La empresa es, por consiguiente, un "organismo vivo" y lo que nos interesa precisar, no es tanto la forma como vive, sino como debe vivir, sin perjuicio de estudiar, aunque sea brevemente, a lo que fué y a lo que es, en la actualidad, o sea, a las etapas que podrían denominarse, de la "empresa precapitalista" y de la "empresa capitalista".

\section{b) La empresa precapitalista.}

El estudio serio y veraz del problema demostrará que la actual empresa tiene, como antecedentes, dos anteriores formas de organización de producción de bienes, que tuvieron vigencia durante dos epocas distintas, en cuanto a organización social politica y económica.

2) MARC, JORGE ENRIQUE - Concepción integral de la empresa en la rev. "Juris" t. 20 pag. 217, "La empresa Comunitaria" en la "Rev. del Derecho del Trabajo" t. XXV (1965) pg. 561 y sgts.

3) RIPPERT, GEORGE - "Les aspects juridiques du capitalisme moderne" - pg. 263 Ed. 1946.

4) DURAND, PAUL "La noción jurídica de la empresa" en la rev. "La Ley" t. 46, pag. 972 y sgts. 


\section{BIBILOTECA DE CIENCIAS JURIDICAS}

La primera, o primitiva forma, fué el llamado "taller familiar" o "patriarcal", donde un número reducido de personas, formando un grupo autonomo y compacto, producían todo lo que era necesário para la satisfacción de las necesidades de ese mismo grupo. Posteriormente, por medio del trueque, primero, y de la venta despues, se produce el intercambio de productos, y ello trae como consecuencia el nacimiento del regimen de la división de la producción, es decir, que cada taller produce determinados elementos, que transfiere a otros, recibiendo, en cambio, otros productos que necesita. También se opera, lentamente, la ampliación e transformación del primitivo nucleo productor, que empieza a estar integrado no solo por personas unidas por el vínculo de la consanguidad y afinidad, es decir dos formas de parentezco, sinó por otras personas servidoras de aquellos, libres y esclavos -, unidos, entonces, por un interes o vínculo económico.

Paulatinamente, entonces, ese taller familiar va a transformarse en taller "corporativo", donde, incluso, el interes econômico prima, donde la repartición e división de la venta del producto, es lo que une a los integrantes de ese nuevo tipo de organización.

El oficio es ejercido, también, como señala Graffier (5), con miras, sobre todo, al cliente, al comprador del producto, o sea, que el grupo no trabaja teniendo en cuenta las necesidades propias de sus integrantes, sinó, los deseos, los gustos, y las necesidades de otras personas, ajenas al grupo productor, o sea, que mientras internamente se mantiene, aparentemente, la misma estructura, se orienta la producción hacia el cliente, que despues, lentamente, se va transformando en "contratista", en una persona que compra la mercadería, revistiendo, a la vez, el doble caracter de beneficiário con la diferencia - intermediario y orientador de la producción, ejerciendo un determinado poder de mando, similar al que, en la actualidad, ejerce el empresario con los trabajadores a domicilio.

Internamente se mantiene la "unidad" del grupo productor, en el sentido del beneficiário y del interes común, transformando-se, unicamente, en vendedor particular o individual, pasando a depender, en la venta del producto, de una persona ajena al grupo, de un intermediário, dejando, en algunos casos, de ser propietário el grupo de la materia prima, e, inclusive, más adelante, de las herramientas que utilizaba.

Esta estructura se mantiene hasta fines de la Edad Media e princípios de la Edad Moderna, pero, a partir de esa época, esta

5) GRAFFIER, J. "Compendio de economía politica" pag. 70/71 ed. 1936. 
unidad interna empieza a resquebrajarse, ya que el maestro del taller empieza a retribuir a sus ayudantes - compañeros, - sin tener en cuenta el valor y precio del producto y mercadoria, naciendo, así, el antagonismo que engendró el hecho de que se perseguira el lucro por distintos camiños: para el maestro, por la venta del producto elaborado, para sus ayudantes, por la retribución que persiguen.

Se separa, así, el interes económico, que hasta entonces habia sido concorde, que se acentua con el transcurso del tiempo, desapareciendo paulatina y aceleradamente, el fraternal anhelo de lucha por intereses comunes. Ya no hay "maestros" y "discipulos", sino "patronos" y "trabajadores".

Este antagonismo se agudiza con la aparición del maquinismo, con la denominada "concentración industrial", y se acentua y llega a su punto cumbre, en épocas más cercanas, con la preponderancia que adquiere uno de los dos factores: el patrono transformado en capitalista, situación que trae aparejada la superindustrialización, la paulatina desaparición del "artesanato libre", del pequeño taller, la concentración en pocas manos del industrialismo frente a un enorme ejercito de "asalariados", a lo que se une la pauperización de las clases intermedias y la proletarización de los colaboradores técnicos.

El predominio del lucro deshumaniza la empresa, la comercialización, que llega a su más alto, nivel en la época subsiguiente, ya se acentuan en el taller corporativo. Por eso el trabajador empieza a ser considerado como "una pieza con responsabilidad limitada y subyugada, con voluntad cohibida".

\section{c) La empresa capitalista.}

Surge, así, lá "empresa capitalista", que se constituye sobre la base de aportación de capitales, es decir, teniendo como fundamento un "patrimonio", que se constituye con la finalidad de explotarlo, es decir, que el fin de la empresa es, concretamente, la utilización del trabajo con el proposito de llegar a la producción de bienes, la obtención de un mayor beneficio económico.

La empresa no es considerada sinó desde el punto de vista económico, $y$, entonces, puede concebirsela como "el organismo que une y coordina los varios elementos de la producción y los dirije a realizarla", caracterizandose por "la mecanización y racionalización" del proceso productivo.

La empresa, así, la "gran empresa", se dedica, ahora preferentemente, al proceso fabril, que reune, en su seno, por una parte, 
cuantiosos capitales que le permiten la instalación de máquinas de gran precio, $y$, por la otra, por un numero grande de obreros empleados y tecnicos, que aportan su esfuerzo humano, necesario para la producción, y, por encima de estos dos elementos, una categoría especial de dirigentes, que tienen a su cargo la compleja tarea de la conducción de la empresa, en un mercado sometido a las variables fuerzas dinámicas de la economía contemporanea.

Se produce, así, ese "gigantismo" economico, esa aglutinación de capitales, esa enorme concentración industrial, nacional primero, internacional, despues, que adquiere no solo un enorme poder económico, sino que pretende influir, como de hecho influye, y más todavía, dirigir no solo la economía nacional, sinó el gobierno político de los estados, creando, así una verdadera dictadura económica. Debe tenerse en cuenta, como denunciara Pio XII, en su enciclica "Quadraggesimo Anno", que ese poder económico, no solo pretende favorecer, con el apoyo del Estado, sus utilidades económicas, sinó resolver las controversias politicas, que se originan dentro de los propios Estados, y entre ellos.

Como tuviera ocasión de señalarlo (6), estos conceptos fueron reafirmados, posteriormente, por Juan XXIII, en su enciclica "Mater et Magistra", al denunciar la existencia de teorias estatales por las que se pretende utilizar ese enorme poder económico-nacional para subyugar a pueblos y naciones, nueva forma de colonialismo totalmente repudiable.

CONCEPCIÓN DE LA EMPRESA.

\section{a) Introducción}

Para poder precisar la forma y manera como debe concebirse y establecerse la "nueva empresa", la "empresa comunitária" despues de haber realizado un estudio de los antecedentes, formas anteriores y actuales de la empresa, conviene realizar un corto estudio sobre los fines, aspectos-economicos y jurídicos, de la empresa en la actualidad.

\section{b) Concepto económico de la empresa.}

Desde el punto de vista económico, puede concebirse a la empresa, siguiendo a Valsechi (7), como "el organismo que une y

6) MARC, JORGE ENRIQUE "La enciclica Mater et Magistra" en la rev. "Juris" t. 19 pg. 305 y sgts.

7) VALSECCHI, FRANCISCO "El trabajo y la reforma de la empresa" en la obra 
coordina los varios elementos de la producción y los dirige a realizarlos", siendo el eje de todo el mecanismo económico, puesto que todo gira en torno de ella, convirgiendo allí todos los factores de !a producción.

Se trataría de una organización de factores de producción, sobre una base capitalista, para aumentar la potencialidad de creación de bienes e para prolongar su duración.

La empresa, en primer termino, no debe confundirse con el "empresario", tesis por la que se inclinan algunos mercantilistas italianos, partiendo de la base que las empresas se forman y conciben "exclusivamente por aportaciones de dinero que convierten por eso mismo, al dinero en empresario", ya que, siguiendo a Haerschal (8), debese señalar que la empresa importa, en realidad, algo inmaterial: "el ejercicio de una actividad" para ciertos fines, mientras el empresario es una persona fisica e jurídica que crea, organiza y explota, aprovecha los beneficios y soporta los riesgos, debiendo tenerse en cuenta que la mayoría de los preceptos legales se refieren, más que a la empresa en si, al empresario, y, por eso, se ha estudiado, aún en el campo económico, más a este último - empresário - que al primero - empresa.

Desde este punto de vista sería, entonces, la empresa, "una unidad económica" de producción, que tampoco debe ser confundida con la "explotación" concepto castizo del termino "azienda" de la literatura jurídico-comercial italiana, es decir: "el conjunto de bienes organizados para la explotación de la empresa; ni con el establecimiento", que es el elemento material de la misma, una parte precisamente, de la "azienda", como aclara Fontanarrosa (9), que en cierto modo podría concebirse como "el local de la empresa".

\section{c) Concepto jurídico de la empresa.}

Como también tuviera ocasión de señalar, cuando a principios del siglo pasado, los redactores del Código Civil frances el llamado, todavía, "Código Napoleón", que despues sirvieran de modelo para la gran mayoría de los paises hispanoamericanos, hubieron de organizar las relaciones jurídicas nacidas de la vida económica, les pareció que se imponía una solución bien sencilla: esas relaciones deberían ser organizadas y regladas por normas de derecho común y estar

"Estudios de Derecho del trabajo" - en memoria del Dr. Alejandro M. Unsaín - pg. 509 Ed. 1954.

8) HERSCHEL, W., Impresa, societá e esercizio "en la Rivista di D. Comerciale" t. 1943 I. 89 pag. 91.

9) FONTANARROSA, RODOLFO O. "Derecho Comercial Argentino" pg. 153 Ed. 1956. 
informadas, a la vez, por estas dos nociones fundamentales: el régimen de la propiedad privada y el contrato.

Estas dos nociones: propiedad privada y contrato, propiedad privada - individualista - y - contrato - relación libre entre dos personas, teoricamente iguales y colocadas en un mismo pié de igualdad, en un mismo plano jurídico, informaron el concepto jurídico de la empresa, es decir, que esta se concebió dentro de estas dos nociones fundamentales: el individualismo, que domina las relaciones entre el empresário-capitalista con cada uno de sus "obreros y empleados", mediante una serie de contrataciones individuales, y el caracter eminentemente privado de la empresa, de las actividades empresariales, completamente desvinculadas y ajenas de toda intervención o ingerencia estatal.

El jefe de la Empresa poseía sobre sus bienes prerrogativas ilimitadas, que le confería el derecho de propiedad. A este título poseía, también, "el derecho absoluto de dirección" sobre los elementos materiales y humanos que habia reunido.

Esta concepción jurídica sufrió, posteriormente, el doble impacto del retroceso del liberalismo y de la crisis del capitalismo.

En efecto, no sólo se le ha restringido las prerrogativas concedidas al derecho de propiedad, sinó que empezó a dudar-se que ese derecho de propiedad pudiera justificar la existencia de dirección de la empresa: primero, porque el derecho de propiedad, derecho real sobre las cosas, no puede explicar un poder de mando sobre las personas, $y$, segundo, porque los bienes no pueden ser utilizados, como precisa Rippert (10), para su goce egoista, sinó que están afectados a un fín económico superior: la producción e circulación de las riquezas. Esta finalidad no puede serle indiferente, ni al Estado, ni al llamado "personal" de la empresa.

La empresa empieza, entonces, a ser considerada como una "sociedad" organizada con miras a un fín.

Debe reconocerse, en este aspecto, en primer termino el valioso aporte de los estudios realizados por J. Berthe de la Gressaye (11), señalando como la empresa, de eminente sentido comercial tendía, paulatinamente, a tornarse en "institucional".

Esta posición fué seguida, despues, por Rippert (12), y, más tarde, por Paul Durand (13).

10) ob. cit. pg. 263

11) BERTHE DE LA GRESAYE, J. "La Transformation Juridique de I'Entreprise" en la "Revue du Droit Social" t. 1939.

12) Autor y obra citada.

13) Autor y obra citada. 
También, dentro del Derecho Comercial, empezó a hacerse la necesaria distinción entre "empresa", en sentido estricto, referida à la explotación, al conjunto de medios de los que se vale el empresario para desarrolar la actividad peculiar de la industria a la que pertenece, con la de "establecimiento", que estaría constituido por la "unidad técnica de producción", e, en otros terminos, siguiendo a Durand y Jausad (14), por la reunión de medios humanos materiales e inmateriales, puestos en acción para lograr mediante una actividad continua, una finalidad de caracter técnico".

Entre este elemento "empresa" y ese otro "establecimiento", es decir, entre la empresa como "unidad economica", dentro del Derecho Comercial, y el "establecimiento" como "unidad de servicio". al servicio de la empresa, actuante en determinado sitio e lugar, existiría un eslabón intermedio, que podría denominarse: "explotación".

Esta distinción entre "empresa", "establecimiento", y "explo. tación", que en el campo del Derecho Comercial tiene, en realidad, una importancia relativa, y solo desde el punto de vista teorico; adquiere sin embargo, singular importancia dentro del Derecho Laboral, en razón de la terminología utilizada por determinada legis. lación, v.g., por la ley argentina n. ${ }^{\circ} 11.729$, reformadora del Código de Comercio, en varios de sus artículos, que se refiere a "la cesión del negocio", y la "transferencia del establecimiento", etc.

Cabe destacar, también, como lo señalara en otra oportunidad, que esta división, mejor dicho esta distinción, ha adquirido, en los ultimos tiempos, jerarquia constitucional, y está expresada en la Constitución Brasileña de 1946, y presenta la ventaja de evitar toda cuestión referente al alcance que debe darse a esta terminología, no solo dentro del Derecho Laboral, sinó, también, dentro del Derecho Comercial y de la Economía, tanto Politica como Social.

Quiere decir, entonces, que dentro del campo del Derecho, el termino "empresa", en sentido generico, comprende a la "empresa", en sentido propio, a la "explotación" y al "establecimiento", y, en ese sentido, es usado por la mayoria de los tratadistas.

Resumiendo, concebida la empresa, lału sensu, como: la unidad economica y juridica que agrupa y coordina factores humanos $y$ elementos materiales de actividad económica, para un fin "determinado", juridicamente debe ser considerada, a mi juicio, como institución", es decir como "una idea que se desarrola en forma jurídica en un ambiente social" y para cuya realización se organiza un poder,

14) DURAND, P. y JAUSSAUD, R. "Traité du Droit du Travail" t. 1. ${ }^{\circ}$ pg. 408 Ed. 1947. 
produciendose entre los miembros que la integran, la idea manifiesta de solidariedad, que son dirigidas por los organos investidos de poder y regulados por procesos adecuados".

La empresa empieza, entonces, a ser considerada, como vengo insistiendo, como una "institución" organizada con miras a un fin.

Constitución y funcionamento de la empresa. Estos son los caminos, como enseña Durand (15), que hay que recorrer, para llegar a tener una visión completa y exacta de la moderna empresa.

\section{III}

\section{LA NUEVA EMPRESA.}

\section{a) La empresa, eje del problema social.}

La empresa se ha constituido, entonces, como lo señala con todo acierto Luis Maire, en el eje de la cuestión social.

La vida de los trabajadores se desarrolla en la empresa, donde actuan durante ocho horas por día, y, por eso, allí, en la empresa, es donde debe verdaderamente ser organizada la colaboración entre Capital y Trabajo, en donde debe buscarse la solución de la cuestión social.

Es la Empresa, en el lugar de trabajo, donde el trabajador conoce las condiciones en que vive día a día, y es allí donde le es posible percibir claramente, el valor de los derechos que merecen le sean acordados y reconocidos, donde puede percibir lo que representa una verdadera colaboración organizada sobre el plano de la profesión, es decir, en una escala en que se encontraran, a intervalos bastantes alejados, los representantes de las delegaciones de los distintos factores de la producción.

Desde el plano de la empresa podrá, despues, ascenderse a la organización socio-política-económica del Estado, y de allí a las soluciones de los problemas, también, socio-política-económica, en el plano internacional.

\section{b) La nueva concepción de la Empresa.}

La nueva concepción de la empresa está naciendo, como señalara Paul Durand (16), dentro de una nueva concepción del mundo, de la vida del hombre y de la história.

A principios del siglo XIX la organización de la sociedad polí-

15) Autor y obra citada.

16) Autor y obra citada. 
tica, "unica y absorvente", estaba a un soberano unico confiada, el qual dominaba una muchedumbre de subditos.

La sociedad moderna, en cambio, se presenta bajo la visión, bajo la forma, de un organismo análogo a los que la fisiologia o la física atómica nos describen.

La organización social y económica se orienta hacia lo que se ha dado en llamar "pluralismo", es decir que en lugar de admitirse sólo la existencia de una sociedad, y, dentro de ella, individuos aislados, se sostiene que esa sociedad civil, Estado, debe integrarse dentro de una gran comunidad supranacional, formada por Estados libres y soberanos, en un mismo pié de igualdad, subordinada al bien comun de la humanidad, y, a su vez, integrada, internamente, no por individuos aislados, sinó por una serie de sociedades - asociaciones intermedias -, grandes e pequeñas, también llamadas "comunidades", que no solo son las clasicas: familia, sociedades políticas, gremiales y culturales, sinó, también, por las actuales comunidades económicas, entre las que, la empresa, como comunidad de trabajo y producción, alcanza su verdadero sentido social y humano.

La empresa, entonces, como "comunidad de trabajo", implica, a la vez, una "comunidad de actividades", una "comunidad de intereses" y una "comunidad de vida", se constituye en personaje importante de la vida socio-económico, en eficaz elemento dentro de la sociedad civil - comunidad socio-política - en que actua, debiendo ordenarse los elementos que la integran, respectando los valores personales y humanos, dirigidos al bien común de la sociedad toda.

Llegase así, a lo que se ha dado en llamar las ascensiones o perfeccionamento de la empresa.

Esta ascención o escalonamiento de la empresa, ya fué precisado por Pio XII en su conecida alocución del 31 de enero de 1952, y reafirmada, posteriormente, si cabe el término, por Juan XXIII, en su enciclica "Mater el Magistra".

El primer escalón está dado por la finalidad económica individual, es decir, en la consideración de la empresa, por parte tanto del trabajador como del aportador del Capital, como un medio idoneo de obtener una "ganancia", un ingreso para su subsistencia y la de su familia.

El siguiente escalón está representado por la finalidad tecnicoeconómico, es la consideración de la empresa como un elemento para el aumento de la producción y de la distribución justa y cristiana, a la vez, de la empresa; la empresa al servicio de la persona humana y del bien común de la colectividad. 
El "bien común" en su aspecto económico, consiste en ese conjunto de condiciones materiales que le permiten y facilitan el desarrollo pleno de la personalidad de los integrantes de una determinada colectividad, en su vida individual, familiar, gremial, cultural, politica y social, incluso espiritual y religiosa.

No debe deducirse de esto que sostenga que el fín primario de la empresa sea el bien común, lo que la convertiría en una entidad de bien público.

Mantengo el critério sostenido hace años: "la empresa entra en el orden jurídico privado de la economía", e, insisto, asi mismo, que: "el fín primario de la empresa es la búsqueda legítima del interés económico de sus componentes" (17).

Lo que pasa es que no debe confundirse "primário", con "primordial".

La empresa es una forma especial de la libre actividad económica, "creación de la iniciativa personal de los ciudadanos", para "la prosecución de los intereses comunes", siguiendo, así, el pensa. miento de Juan XXIII, pero dirigida "al bien comun de la colectividad".

La función y misión del Estado, garante del bien común de todos sus integrantes, en este aspecta, como en otros, solo es "coadyuvante e integrativa". No es su misión absorver las empresas privadas, sinó coordenar los esfuerzos, en procura, precisamente, del bien común de sus integrantes.

El hecho, sin embargo de que la empresa sea, fundamenta!mente, de Derecho Privado, no quiere decir, tampoco, que el Estado no pueda legislar, reglamentando ese derecho, refiriendose no solo a la parte interna de la misma, a las relaciones que deben existir entre empleadores - empresarios - y trabajadores, estableciendose, incluso, un régimen de participación de estos últimos en los bene. ficios, gestión y hasta propiedad de la empresa, sinó, también de lo que podría denominarse la parte externa de la empresa, es decir, para que esta se oriente en la prestación de bienes y servicios necesarios para la comunidad.

La empresa, entonces, podrá cumplir con el fin individual y social, a la vez, y servirá al bien común de la colectividad nacional, dentro de la cual actua, sin dejar de tener en cuenta las necesidades de tôda la humanidad.

La empresa debe estar orientada, entonces, no por el sentido de

17) MARC, JORGE ENRIQUE "La empresa comunitaria" pg. 561. 
la producción como lucro, como lo sostuviera el capitalismo, ni con la producción como poder, como lo sostiene el marxismo, sinó de la producción como servicio.

La empresa debe estar al servicio del hombre, y sujeta, como entidad jurídica y económica a la ley moral.

El hombre debe volver a ser sujeto y fín de la empresa, como de toda economía, y los fines económicos deben estar subordinados al fín o bien ultimo de la persona humana, para que esta pueda realizar plenamente su destino terreno y transcendente.

\section{IV}

\section{LOS ELEMENTOS DE LA EMPRESA.}

\section{a) Los elementos humanos de la empresa.}

La empresa está constituida, como se ha dicho, por un conjunto de elementos humanos y un conjunto de medios materiales, ordenados a un fín.

Pero, indudablemente, dentro de la nueva concepción de la empresa, esta comprende, antes que nada, un conjunto de elementos, humanos, como también he venido insistiendo, no existe ningún organismo sinó en el pensamiento de los hombres que la constituyen, conciben y animan.

Y es en este campo de las denominadas "relaciones humanas", dentro de la Empresa, en donde se está produciendo, una autentica "transformación", una veradera "revolución", en el concepto y concepción de la empresa, que repercuta tanto en su estructura como en su funcionamento.

Dentro de la concepción capitalista, la empresa era considerada, fundamentalmente, como una prolongación juridico-económica del empresario-capitalista.

En el interior de esa "unidad productiva", existen también, como lo he venido señalando, dos tipos bien diferenciados de relaciones jurídicas: a) la relación social que liga, entre sí, a los aporta. dores del capital, dueños de los medios de producción, constituyendo así. una sociedad jurídico-economica, más que jurídico-comercial; y b) del otro lado, una série de relaciones individuales, de tipo laboral, que vinculan el empresario-capitalista, persona física e moral, con una serie de trabajadores, en relación de subordinación o dependencia.

La relación social-societaria, constitutiva de la sociedad comercial, era totalmente distinta en su esencia y naturaleza, de las relaciones 
individuales-laborales, basadas, pura y exclusivamente, en la prestación de servicios, para la explotación de los medios de producción.

La "comunidad capitalista" era, entonces, para dicha concepción, concreta y jurídicamente, la Empresa.

Los trabajadores, incluso los tecnicos y el personal directivo, no formaban parte de la misma; eran, simplemente, personas vinculadas a la misma en virtud de un contrato, pero sin integrarla, actuando en determinada función o tarea, percibiendo una remuneración, o sea una determinada suma de dinero, como contraprestación, denominada, asimismo, sueldo, salario, remuneración, e, incluso, comisión, porcentaje y hasta "participación en los beneficios".

Esta situación ha creado, y sigue creando, una verdadera tensión permanente, dentro de la Empresa, entre los capitalistas, cuyo objetivo principal es la obtención del máximo del beneficio con el mínimo de gastos, y los trabajadores a quienes solo interesa percibir el mayor salario con el minimo esfuerzo.

Por eso llegué (18) a afirmar que esta tensión permanente, en el seno de la empresa, en la estructura de la empresa, hace que en la nueva concepción, "la empresa comunitaria", la transformación debe operarse no solo en la parte externa, sinó, fundamentalmente, en la parte interna de la misma.

Esta cuestión de las relaciones humanas, dentro de la empresa, no debe entenderse meramente, como "la relación directa que se establece entre el trabajador y el patrono, con el objeto principal que aquel el trabajador - "le sean reconocidos todos los derechos que le corresponden y pertenecen como tal", que le sean estimadas - entendidas "todas sus inquietudes y esperanzas, sus deseos de una vida mejor", como sostiene Mons. Pietro Pavan, "para que cada operario pueda gozar de su propio trabajo", sino también, y sobre todo a "la existencia de una verdadera y real participación en los destinos de la empresa", como sostuviera Juan XXIII en su enciclica "Mater et Magistra", y lo reitera, mas recientemente, Paulo VI en la "Populorum Progressio".

Las relaciones humanas estables, constructivas, entre trabajado. res, tecnicos y capitalistas, no son posibles, señalaba acertadamente Leon y Leon (19), si los primeros no estan organizados sindicalmente, libres de toda dominación estatal o capitalista; y si tales organizaciones no son reconocidas y aceptadas por el Estado y por los emplea-

18) Autor y obra citada.

19) LEON Y LEON, BERNARDINO "Relaciones de personal" en la rev. "Gazet del trabajo" t. 1961 - pg. 239. 
dores, como representativas de los trabajadores, incluso, si sus organismos no son reconocidos como integrantes de la sociedad económica.

En una palabra, la nueva concepción de la empresa, concepción social y comunitária, parte de la base de que esta debe dejar de ser una mera "sociedad de empresarios-capitalistas" para convertirse, paulatina pero inevitablemente, en una "unidad vital", en una verda dera "comunidad de trabajo", formada e integrada por todas aquellas personas que aportan, respectivamente, bienes materiales, trabajo y capacidad tecnica o directiva, cooperando, mancomunada y solidariamente, en la obra de producir bienes, al servicio de la comunidad nacional e internacional.

\section{b) Distintos regimenes de relaciones}

$\left.1^{\circ}{ }^{\circ}\right)$ El régimen salarial.

Las relaciones entre Capital y Trabajo, dentro de la Empresa, en el rógimen actual, pueden cristalizar-se en distintas formas, partiendo del régimen salarial, que es el más común y generalizado, pasando por distintas formas intermediarias, hasta llegar al sistema o régimen de sociedad, que es muy poco usado.

El contrato de trabajo, el contrato individual de trabajo, tal como se lo concibe dentro del régimen o sistema liberal capitalista es, en realidad, una forma de relación económica entre un trabajador y un empresario, mejor dicho, entre trabajo y capital, por el cual la propiedad, la dirección, los riesgos y beneficios de la empresa corresponden, por derecho, a los titulares del capital, mientras los trabajadores, una vez percibido el salario o retribución pactada, juridicamente, no tienen ningun otro derecho.

Este sistema salarial, es, debo señalarlo, anterior a la empresa capitalista, ya que se presentó, como lo destacara, aunque en forma restringida, dentro del taller medieval, al finalizar dicho periodo histórico, o más concretamente, en los comienzos de la Edad Moderna, si se quiere, como enseña Fanfani. (20).

Concuerdo, en cambio, con Legaz y Lacambra (21), que la concepción del contrato de trabajo, sobre todo su concepción juridica, no puede ser estudiada fuera del clima político-sociológico al que debe su vigencia, y podría decirse su permanencia, clima que se caracteriza por la nota general de un individualismo que se

20) FANFANI A.

21) LEGAZ Y LACAMBRA, L. "Estudios de doctrina jurídica y social" - pág. 243 Ed. 1940. 
manifiesta bajo distintas formas. A esto se debe, precisa el citado maestro español, que la categoría fundamental en esta materia, haya sido el contrato, cuyo objeto es el trabajo.

El contrato, este concepto fundamental de la tecnica juridica tradicional, se convirtió a la larga en la categoría vital primaria de la vida liberal burguesa. De esta concepción de la vida que convierte al individuo en la única realidad social, es decir, que no se limita a afirmar, como verdad indiscutida e indiscutible, de que lo social no puede ser pesado como real si se prescinde de lo individual, ni se limita, tampoco, a la afirmación, cierta, también, de que sobre lo social flota, inexorablemente, un manejo de valores de intimidad personal, que no solo son irreductibles a lo social, sinó que son positivamente superiores a todo valor colectivo.

Partiendo de la existencia, indiscutible, de que este régimen o sistema tiene algunas ventajas - la principal de las cuales es asegurar el ingreso al patrimonio del trabajador de determinados valores: el pago del salario, normalmente, de una determinada suma de dinero, mensual, quincenal o semanalmente, se oponen, indublamente, a determinadas normas de justicia y equidad, que reclaman que el producto común, se reparta de una manera proporcional entre todos aquellos que han participado en su producción.

La defensa del régimen salarial se funda, se pretende fundar, al menos, en un hecho evidente: el trabajador tiene necesidad de percibir, con seguridad, un ingreso con que pueda hacer frente a sus necesidades y a las de sua familia, ya que, normalmente como lo señalara Pio XII en su enciclica "Quadraggesimo Anno", no tiene otros medios de subsistencia, y, por eso, cede los derechos que eventualmente pudieram corresponderle en la venta del producto futuro, a cambio de una percepción presente, estable y segura, que le garantiza la empresa. Quiere decir, entonces, que, de esta forma, una participación futura, incierta en la venta del producto, se cambia - sustituye, por una percepción presente y cierta, con lo cual el riesgo económico directo se desplaza totalmente hacia el factor capital.

Frente a esta aparente ventaja, cabe señalar que el régimen salarial presenta una serie de inconvenientes de distinto orden: sicológicos, económicos y sociales, a saber: a) el trabajador se siente, por que en realidad lo es, un extraño con respecto a la empresa; b) por eso no se interesa, o se interesa poco, por la buena marcha, perfeccionamiento, conservación, etc., de la empresa, de los materia- 
les, de la ejecución de la obra, etc; c) la existencia de una falta de colaboración entre patronos y trabajadores, puede llegar, como de hecho llega, a verdaderos enfrentamientos; d) y que existe entre ellos un distanciamento sicológico: la formación de una conciencia, que mantiene ese clima, proclive a la lucha de clases.

Deseo señalar, antes de seguir adelante, y para evitar equivocos, que no pretendo enjuiciar in totum el régimen salarial, y menos proclamarlo injusto en su misma naturaleza, como se sostuviera en el recordado "Katholikentag" - Congreso Central Catolico -, en su proclama del 4 de septiembre de 1949, celebrado en la ciudad alemana de Bochun, al que se adhirió el "Evangelischer Kirchentag" - Congreso General Evangelista -, celebrado en el año siguiente, en otra ciudad alemana, Essen, que al afirmar la exigencia, derivada del mismo Derecho Natural, a la corresponsabilidad y codeterminación de todo trabajador en su trabajo, aunque sea sobre bienes ajenos, recibió, la primera, las más serias amonestaciones pontificias.

En efecto, en este punto la doctrina social-cristiana no deja lugar a dudas: el contrato de trabajo no es injusto por naturaleza.

Este principio fué declarado expresamente, con serenas palabras, por Pio XII en su enciclica "Quadraggesimo Anno", interpretando, a su vez, determinados aspectos de la "Rerum Novarum" de Leon XIII. Por su parte Pio XII, referendó expresamente esta doctrina, en varias oportunidades, pudiendo citarse, entre otras, en su discurso del 3 de Junio de 1950, al sostener: "los que condenan el contrato de trabajo como injusto por naturaleza y dicen que por esta razón hay que sustituirlo por el contrato de sociedad, hablan un lenguaje insostenible".

No debe confundirse, también conviene aclararlo, estas expresiones como contrarias con las de Juan XXIII, en su conocida "Mater et Magistra", donde precisa que si bien "una concepción humana de la empresa debe, sin duda, salvaguardar la autoridad y la necesaria eficacia de la unidad de dirección", no es menos que "no puede reducir a sus colaboradores de cada día a la condición de simples silenciosos ejecutores, sin posibilidad alguna de hacer valer su experiencia, enteramente pasivos respecto a las decisiones que dirigen sus actividades" (22), premisas que coinciden exactamente, con las precisadas en la "Constitución sobre la Iglesia en el mundo de hoy" - sec. II, n. ${ }^{\circ} 68$-, documento elaborado y aprobado en el II Concilio

22) JUAN XXIII, "Mater et Magistra". 
Vaticano, donde se insiste que: "salvada siempre la necesaria unidad de dirección de la empresa, se debe promover "mediante metodos que se deben determinar adecuadamente, la participación activa de los trabajadores en la dirección de la empresa", agregandose que esta participación es fruto de su condición de hombres libres, con derechos propios, creados a imagen y semejanza de Dios".

En una palabra, debe partirse de la base que el régimen salarial, no solo no es el único, sinó tampoco el más justo, ni mucho menos la forma más perfecta de cristalizar las relaciones entre capital y trabajo, dentro de la empresa.

2.) El régimen de sociedad.

Desde hace más de 40 años se viene acentuando una corriente que propugna el establecimiento de un régimen más en consonancia con la dignidad del trabajo del trabajador, más eficaz para asociar estrechamente esos dos factores de la producción, como se sostiene, debo destacarlo, en un valioso estudio realizado en España por el "Instituto Social Leon XIII", que vengo siguiendo en forma prevalente, en esta parte del presente estudio (23).

En contraposición con el contrato salarial, los beneficios y la gestión de la empresa corresponde a todos los socios.

Este contrato, aunque en forma rudimentaria, e inadecuada a las necesidades de la hora, esta previsto en art. 383 y sgts. del Código de Comercio, vigente en la República Argentina, bajo la denominación de "Contrato de capital e industria", y también, en la gran mayoría de los códigos mercantiles de los países ibero-americanos.

Este contrato de sociedad, aplicado en toda sua extension y alcance, a las relaciones laborales, ofrecería muchas dificultades, en su aplicación, y, por el momento, debe reconocerse, podría ser praticamente imposible, dentro de nuestra organización actual, o sea, que correspondería el dictado de una ley especial, promoviendo una prudente combinación del régimen salarial con el sistema de sociedad, sistema intermediário, de transición, que reuniria las ventajas de ambos sistemas, evitando, en lo posible, al mismo tiempo, sus inconvenientes.

Los elementos del contrato de sociedad, a los que ordinariamente se refieren los autores, y que habrían de introducirse en el sistema salarial, son, concretamente, tres: a) la participación en los

23) INSTITUTO SOCIAL LEON XIII, "Doctrina social catolica" pag. 206 Ed. 1959. 
beneficios, b) la participación en la gestión o dirección y c) la participación en la propiedad de la empresa.

La progresiva y paulatina transformación del contrato de trabajo, su integración con elementos del contrato de sociedad, traería aparejado, según Von Estel (24), las seguientes ventajas: a) pondría fin a la supremacía del capital y del espiritu capitalista, que implica la preeminencia del dinero sobre el hombre, del capital sobre el trabajo, del interés privado sobre el interés común, assegurando al trabajo su parte en la gestión de la economía, y contribuyendo, prevalentemente, a la humanización de las relaciones entre los distintos factores de la producción; b) partiendo de la base que son insuficientes los otros medios ensayados para mejorar y modificar las mencionadas relaciones humanas, y, hasta en algunos casos. contraproducentes, indudablamente, debemos inclinarnos por esta solución, que se ajusta, además, indudablemente, a un pensamiento de Justicia y de Liberdad, señalandose que, tanto el "paternalismo" de los propietarios de la empresa - tan difundida a principios del siglo, y aconsejada, incluso, por algunos social-cristianos, la acción sindical de las asociaciones profesionales, la intervención directa del Estado - incluso la dirección y control estatal que representa la máxima expresión de esa tendencia -, la llamada organización corporativa, etc., no han llenado los fines que se esgrimieron en su momento, pudiendo señalarse que no solo no suprimieron el "proletariado", ni la lucha de clases, sinó, más bien contribuyeron a consolidar su existencia, acentuándose más, si cabe, las diferencias entre las distintas clases socio-economicas; c) la estructura jurídica de la empresa, especialmente de la gran empresa, no corresponde a la realidad social, ya que de hecho la propiedad de las mismas que pertenece legalmente, a los aportadores del capital, "accionistas", en su gran mayoría permanecen totalmente al margen de la vida de aquellas, delegando toda sua autoridad y responsabilidad, en los consejos de Administración, que, a su vez, los hacen en el "gerente" que, en realidad, es, aunque no jurídicamente, quien lleva la dirección de la empresa, de esa gran sociedad anonima constituida en empresa, de esas "sociedades sin alma", como las denominara acertadamente, Pio XII; d) el contrato de sociedad dá realce a la cooperación que debe existir entre Capital y Trabajo; y e) el contrato de sociedad responde mejor a la conciencia de los trabajadores, como clase socio-económica, a la consciencia que tienen, en la actualidad los trabajadores, con sentido de dignidad, de responsabilidad, de cultura y de progreso.

24) VON GESTEL, R. "La doctrina social de la Iglesia" pag. 259/62. - Ed. 1959. 


\section{V}

\section{LA PARTICIPACIÓN ACTIVA DE LOS TRABAJADORES EN LA EMPRESA}

\section{a) Encuadramiento.}

El analisis de la nueva empresa, comporta, siguiendo a Sierra Bravo (25), el estudio de varios temas fundamentales.

El primeiro de ellos es, indudablemente, el valor que debe darse a la persona humana, dentro de la empresa.

El hombre es origen, principio dinamico y fin de la empresa. La empresa, en concreto, no es sinó, como he venido insistiendo, "una creación de la voluntad de los hombres".

Pero la persona humana, no es solo causa eficiente del ser de la empresa, sinó, también, de su vida, de su actividad y movimiento. La empresa no tiene movimiento propio. Las maquinas, aún las más perfectas, y los valores económicos, aunque esenciales pertenecen al mundo de los seres sin alma. La empresa, entonces, debe ser animada por la inteligencia, la voluntad y el esfuerzo de todos los hombres que la constituyen.

Por eso puede decirse que el elemento formal de le Empresa esta dado por el material humano; por eso, insisto, debe subrayarse que "los trabajadores forman parte de la empresa", pertenecen a ella, no son elementos exteriores y accidentales sinó que la integran, y "participan" de ella.

La participación activa de los trabajadores constituye, en la actualidad, la solución propugnada, desde distintos puntos de vista, para la solución de los problemas dentro de la Empresa, aunque, en realidad, como lo destacara, se trata de la reforma de la estructura, sobre todo mental de la empresa, de una versión integral de la misma, se es sentido que alcanza, en que se está dado en llamar, el "Participismo", teoria que alcanza no solo a la estructura de la Empresa, sino de toda la organización socio-política-económico del futuro.

"Participar", en realidad, literalmente hablando, en sentido gramatical, es recibir de otro lo que no se tiene de por si por la propia esencia y naturaleza específica o sea, como precisa Urdanoz (26),

25) SIERRA BRAVO, R. "La persona humana en el magisterio social de Pio XII" pag. 226 Ed. 1960.

26) URDANOZ, TEOFILO L. "La participación activa de los obreros en la vida de la empresa", en la obra "Problemas morales de la empresa en relación con el trabajo" pg. 215 Ed. 1963. 
que no se es totalmente esa cosa, que tampoco se posee en totalidad de la misma, sinó que, siendo el sujeto participante, distinto, recibe, añadida, una parte de esa forma o función que participa".

La idea de "participación", no solo penetra todos los aspectos ontologicos creacionistas, según la filosofía tradicional cristiana, sinó que con razón puede atribuirsele a todo el ámbito de comunicaciones de formas y funciones humanas. Por eso señala el citado tratadista, la palabra "participación" designará en cada caso la parcial recepción de un atributo o función por aquel que no lo posee como propia, sinó que la tiene como "comunicada" y derivada de quien la posee en realidad, $y$, sobre todo, en plenitud.

Sin embargo, en el caso de las relaciones humanas, no solo dentro de la Empresa, sinó en otros aspectos o formas, el termino "participación" se entiende como sinónimo o similar de "asociación" ○ "cooperación".

Asi las expresiones contenidas en la enciclica "Mater et Magistra" - y reafirmadas, según se ha dicho en el Concilio Vaticano II - "participar abiertamente" en la vida de la empresa, tiene, si nos atenemos al texto latino, ese marcado matiz de "asociación" y "colaboración" en la vida del trabajo, aclarandose que los trabajadores tienen el derecho no solo de hacerse "oir" presentando sus sugestio. nes y aspiraciones, sinó que es muy conveniente y oportuno, que sean asociados y aporten su colaboración en el desarrolo de la misma, o sea, sigue enseñando Urdanoz (27), elevados a la condición o rango de asociados a la gestión de la empresa, participando activamente dentro de la misma, es decir, que deben recibir una parte de las funciones, derechos y garantias o atribuciones así como los frutos de aquel o aquello a quien se asocian.

En una palabra, los terminos "participación", "asociación" y "colaboración", si bien no son sinónimos, son utilizados tanto en el campo doctrinario como en el legislativo, para señalar "la presencia activa de los trabajadores en la empresa", pudiendo señalarse que en la XVI Conferencia Internacional del Trabajo, reunida en Filadelfia (E. U. N. A.) en 1944 se aprobó, como fín y objetivo de la Organización Internacional del Trabajo, entre otros, la obligación de fomentar entre todas las aciones, programas que permitan establecer: "la cooperación de empleadores y trabajadores para mejorar continuamente la eficacia en la producción y la colaboración de los trabajadores y empleadores en la preparación y aplicación de medidas sociales y económicas", norma internacional que, conjuntamente con el principio consagrado en la IX Conferência Internacional Americana,

27) Autor y obra cit. pag. 216. 
celebrada en Bogotá (Colombia), en 1948, sirvieron de antecedente inmediato a los terminos "participación" en las ganancias de la empresa, como control de la producción y colaboración en la dirección, que se consignan en el llamado art. 14 bis o nuevo, de la presunta reforma constitucional argentina de 1957.

Esta promoción de los trabajadores parte, debe partir, al menos, en mi concepto, de la necesidad de la realización de una nueva estructura de la empresa, señalandose que si bien existen como vengo insistiendo, tres formas de participación, estas tres formas de participación, en realidad, se relacionan entre sí, como medios a un mismo fín, reiterando que la participación de los trabajadores se concreta em una mayor abundancia de los frutos de la producción o beneficios de la empresa, que la lleva a un aumento de riquezas y accesos a la propiedad privada, constituyendo el fín y meta de su promoción social, reiterando también, que guardan entre si una relación de medios a fín; o sea que la participación de los beneficios conduce paulatinamente a la copropiedad, ya que los bene ficios distribuidos pasan a constituir un nuevo capital de producción o una parte de la propiedad de la empresa, y, siendo así, los traba. jadores "coproprietarios" de la "empresa", deben ejercer, aunque sea parcialmente, un derecho de "cogestión" e codirección en la misma. Por eso, estimo incongruente, y falto de lógica, la opinión de quienes admiten y propugnan la participación en la dirección, sin la participación en los beneficios, ya que como se sostuviera en el seno de la Convención Constituyente argentina de 1957, "el control en la producción se refiere al medio de determinar la parti. cipación en las ganancias, a objeto de garantizarla" señalandose que "la colaboración en la dirección se habia consignado al solo efecto de asegurar al trabajador la participación de las ganancias de la empresa" (E. Ses. pags. 1444/45,) siendo interesante destacar que solamente los convencionales comunistas, entre ellos F. Rodolfo Chioldi, solicitaban la exclusión de la "participación en los beneficios", mientras propugnaban la "participación en la dirección".

$1^{\circ}$ ) Participación en los beneficios.

En realidad el sistema de participación en los beneficios o en las utilidades, puede, como de hecho ocurre, ser aplicado sin que, por ello, sea necesario e imprescindible modificar las estructuras de la empresa.

Según la O.I.T. se trata, más bien, de "un metodo de remuneración", en virtud del cual "un empleador asigna a su empleado una parte en las utilidades netas de la empresa, además de sus salarios normales". 
Esta forma de participación, si bien produce, prima facie, la impresión de transformar el contrato de trabajo en contrato de sociedad, no lo es, en realidad, ya que no modifica su naturaleza, es decir, no altera la indole del vínculo existente entre las partes, pudiendo incluso, decirse que no existe contrato de sociedad por que falta, precisamente, el "affectio societatis", que caracteriza a este contrato.

En concreto, concordando con Cabanellas (29), señalo que "la participación en los beneficios, en sí misma, es solamente una forma o manera de retribuir al trabajador, un medio o forma de pago, asimilable al salario diferido, una variedad integradora del salario, dentro del contrato de trabajo, que se mantiene con todo su alcance y afectos.

La participación en los beneficios o en las utilidades o en los resultados, nació, según la opinión más generalizada, en Francia, alrededor del 1842, cuando un empresario - "maestro pintor" - Jean Leclaire, concibió el sistema, mejor dicho lo empezó a practicar. como estimulo para aumentar el rendimiento de sus trabajadores.

Fué impulsado Leclaire por un sentimiento y la preocupación por la justicia social, o más bien, pensó que una remuneración suple. mentaria de este tipo, incitaría a los trabajadores a aumentar su productividad, de lo que resultaría, a la postre un beneficio mayor para el empleador que la parte que habia dejado de percibir y entregado al trabajador.

Lo que importa destacar es que, a partir de esa fecha cundió un entusiasmo general por el sistema, frente al éxito obtenido por Leclaire - el aumento de la producción y de las ganancias, y varios empleadores, imbuidos, sobre todo, de la doctrina paternalista, empezaron a aplicarlo, voluntariamente, primero en Francia y des. pues en Inglaterra.

Precisamente, en virtud de esa corriente, se sostuvo sobre tods en los primeros tiempos, que la participación en los beneficios debia ser libremente otorgada por los empresarios, o cuanto menos, surgir de contratos libremente pactados entre las partes, voluntariamente convenidos, sin obligación legal, y mucho menos, impuesta imperati. vamente por el Estado, llegandose a sostener que su obligatoriedad, perderia su razón de ser, siendo interesante destacar que la ley francesa del 26 de abril de 1917, que lo establecia para las empresas

28) CABANellas, Guillermo "Contrato de trabajo. Parte General" Vol. II pag 68 Ed. 1963. 
industriales, precisaba que su aplicación quedaba reservada "a la buena voluntad del patronazgo".

En los ultimos tiempos, sobre todo con posteridad a la guerra mundial de 1939/45, el régimen o sistema de participación en los beneficios de la empresa ha sido establecido, no solo en varios textos constitucionales de ispanoamerica - Brasil, Bolivia, Ecuador, Peru, Argentina, etc., como declaración de tipo o carácter programático, sinó también, en algunos Códigos Laborales, como la "Ley del Trabajo" de Chile, la "Ley General de Trabajo" de Venezuela, el "Código de Trabajo" de Colombia, etc., como norma de carácter obliga. tório, y, en España, por medio de leyes especiales.

También el sistema de la participación en los beneficios, con carácter obligatório, ha sido impuesto en distintos países europeus, como Belgica (1948), sobre todo en la República Federal Alemana (1951, 1956), etc., por su parte el actual gobierno frances, pese a una serie de leyes especiales dictadas, sobre todo, durante el lapso compreendido entre 1951 a 1956, ha acabado de insistir sobre la necesaria aplicación del régimen "particionista" dentro de las empresas, tanto publicas como privadas.

La nueva república Italiana, en cambio, no ha dado cumplimiento, hasta la fecha, a la declaración programática consagrada, al respecto, por el art. 46 de la Constitución de 1948.

Tanto en Gran Bretaña, como en los EE.UU. de America, y Suecia, si bien no existen disposiciones legales al respecto, ni siquiera que lo aconsejen, la participación de los trabajadores en los beneficios de las empresas se vienen aplicando por medio de disposiciones insertas en distintos convenios colectivos de empresa. Cabe señalar que en los EE.UU. varias importantes asociaciones profesionales de empleadores se han manifestado contrárias a este sistema, sosteniendo que ello importaría, en cierto modo, restringir, limitar o disminuir el principio de autoridad del capitalista en la dirección de la empresa, ya que la participación en los beneficios traería aparejado, inexorablemente, la participación de los trabajadores en la dirección o gestión de la empresa, o sea, que la oposición se finca más en la "cogestión" que en la participación de los beneficios en si misma.

Aúnque parezca extraño, también en la U.R.S.S., pese a su régimen económico, basado en la supresión o abolición del régimen de propiedad privada, existen, en la practica, problemas similares a los existentes en los paises "capitalistas", es decir divergencias y diferencias entre los "trabajadores" y los administradores 
de las empresas que han dado lugar al dictado de disposiciones sobre funcionamento de comites sindicales, de fábrica y de producción.

Cabe precisar que, de acuerdo a la mayoría de los textos legales en vigencia, los trabajadores tienen derecho a controlar la contabilidad de la empresa, para garantizar la veracidad y exactitud de las liquidaciones.

Como encaran L. y J. Danty Lafrance (29), los rasgos caracterizan el sistema de participación en los beneficios: a) que para que se de realmente participación en los benefícios es necesario que la parte que se atribuye al personal y su modo de repartición estén determinados con anterioridad, y, en el caso de ser voluntários, el personal debe haber dado, también, con anterioridad, su conformidad, y a que de lo contrário, es decir, si el empleador es quien fija arbitrariamente el monto de dicha participación se trataría en realidad, de una simple gratificación; y b) que la determinación del modo de calcular los beneficios debería, igualmente, hacerse con conocimiento - control - del personal, debiendo tenerse en cuenta que, precisamente, es en este aspecto, donde se encuntra, la mayor resistencia de los empresarios.

2. ${ }^{\circ}$ Participación en la gestión. - Cogestión.

Debe entenderse por "participación en la gestión" o "cogestión", en sentido lato, toda forma de intervención de los trabajadores, como tales, en actos que afectan al gobierno o la dirección de la empresa, es decir, como precisaba Valsecchi (30), "la participación de los trabajadores, junto con los empresarios-capitalistas en el poder de decisión, dirección y administración de la "empresa", pudiendo ser la misma total o parcial.

Como precisa Rodrigues Mancini (31) supone el reconocimiento, por parte del empleador, mejor dicho, por los capitalistas de la empresa, de que los trabajadores no son subordinados pasivos, sinó "colaboradores activos suyos", o sea que acepten que los trabajadores participan, junto con el empleador, en la decisión de aquellas cuestiones que afectan al gobierno de la empresa.

Cabe señalar, sin embargo, que tampoco la cogestión, lału sensu, representa, por sí misma, una modificación substancial de la actual formación empresaria, ya que la propiedad de la empresa sigue en manos de los capitalistas, o sea, como precisan Hueck y

29) DANTY LAFRANCE L. y J.

30) Autor y obra cit.

31) RODRIGUES MANCINI. 
Hipperday (32), si bien la "cogestión", que sería mejor denominar "codecisión", existe, sobre todo, un fenómeno sociologico y humano, no puede afirmarse de que se haya producido una transformación radical de la estructura de la empresa, en su aspecto económico c sea, que, "la estructura organizativa de la empresa" se mantiene, respectando el caracter "obligacional" de las relaciones de trabajo y de propiedad privada empresarial..."

Para la mayor claridad conviene, ahora, realizar un pequeño esquema de los distintos tipos o "forma" de participación en la gestión de la empresa.

a) Por el grado de participación.

$\left.1 .^{\circ}\right)$ Informativa: el trabajador es meramente informado de las actividades de la empresa, pero no tiene ni voz ni voto.

$\left.2 .^{\circ}\right)$ consultiva: el trabajador tiene conocimiento y voz, pero no voto. A su vez esta participación, de caracter consultivo, puede ser, a su vez, discrecional y obligatória, es decir, nacer de un acto potestativo del empresario-capitalista, o bien deberse a una disposición legal o convencional.

$\left.3 .^{\circ}\right)$ decisoria: es una verdadera codirección. El trabajador tiene voz y voto en las desiciones de la competencia.

b) Por la extensión de la competencia.

$\left.1 .^{\circ}\right)$ limitada a los asuntos extraeconómicos; cuestiones laborales, de caracter social, tecnica, etc.

2. ${ }^{\circ}$ económica: cuando se extiende a todos los asuntos inclusive los comerciales y financieros.

c) Por la forma de establecerse.

$\left.1 .^{\circ}\right)$ expontanea: cuando es el empresario capitalista quien la establece voluntariamente.

$\left.2 .^{\circ}\right)$ contractual: cuando es fruto de un entendimiento y el acuerdo se cristaliza en un convenio colectivo.

3..$^{\circ}$ impuesta: cuando es el estado, por medio de una ley quien la impone. También puede ser la organización sindical, quien la impone, aunque dentro de una organización democrática, para ser obligatoria, debe asentarse en un convenio colectivo.

Conviene precisar, por último, que muchos autores reservan el nombre o designación de "cogestión a la participación en la gestión, cuando a la vez, es decisoria y económica, forma esta la mas dificultada y sobre la que se adentran todas las discusiones.

32) HUECK ALFREDO. 
Por mi parte, estimo, que puede hablarse de "cogestión" lału sensu, que es, como lo he hecho, comprensible de toda espécie de participación en la gestión, utilizando en cambio, el termino de "cogestión", strictu sensu, para la que reuna, a la vez, el doble carácter señalado.

También puede analizarse el problema de la gestión en la empresa, desde distintos puntos de vista, a saber: a) jurídica, b) sicológica, c) económicos, d) sociológicos, e) morales.

Desde el punto de vista jurídico, la gestión en la dirección, es decir, el derecho a participar en la dirección de la empresa, está intimamente ligado con el sentido jurídico de la empresa, tema que ya ha sido estudiado, desprendiendose de ello, que dicha participación no puede ser estudiada, ni puede emitirse juicio valedero sobre su naturaleza jurídica, sinó en razón y vinculandola estrechamente al concepto jurídico de la empresa.

Ahora bien, para quienes inclinamos por la conceptualización de la empresa, como "ente jurídico", dentro de la teoría institucionalista, el problema juridico de la participación de los trabajadores en la dirección de la empresa, es facil de resolver.

En cambio, dentro de la actual organización socio-política-econó mica, el derecho a participar en la dirección de la empresa, nace, en la República Argentina, como en otros paises, de una disposición constitucional - art. 14 bis de la reforma de 1957, dentro de la sana interpretación que debe darse al mismo.

En cuanto a si la participación de los trabajadores en la dirección de la empresa, es o no de derecho natural, de acuerdo a la doctrina social catolica, debo remitirme a lo sostenido sobre la justicia del contrato de trabajo en si, o sea, que la Iglesia, hasta el momento, se ha limitado a aconsejar "la paulatina transformación del contrato de trabajo en contrato de sociedad" siguiendo así la doctrina sentada ya por Pio XI, que ve con buenos ojos y recomienda la participación expontanea y contractual, cualquiera que sea su grado y extensión, defendiendo, asimismo, la necesidad de la participación en su sentido estricto de las empresas nacionalizadas", adoptando, en cambio, una postura de reserva ante la cogestión económica y decisoria, impuesta, como medida general, por el estado e por $\in$ l sindicato, en las empresas privadas, cuando, de alguna manera, ataca a la esencia del derecho de propiedad, y pueda generalizar los metodos colectivistas, reiterando que en cambio, el Derecho Na. tural exige que los directamente interesados - capitalistas y trabajadores -, fijen en norma consensual los terminos que hayan de 
regular sus relaciones, en el seno de la empresa, buscando el bien comun de los interesados y de la comunidad. Es claro que estas expresiones deben correlacionarse con las citadas resoluciones adoptadas en el Concilio Vaticano II.

Desde el punto de vista económico, el problema de la cogestión, latu sensu, influye, indudablemente, sobre la producción y constituye, como recuerda Rodrigues Mancini (33), no solo el instrumento poderoso del progreso económico de los integrantes de la empresa, sinó un remédio de los problemas humanos y un factor importante, no esencial ni menos exclusivo, del desarrolo económico de la comunidad.

En cuanto al aspecto sociológico, debe tenerse en cuenta, también la moderna doctrina sobre el sentido social de la empresa, es decir, que debe organizarse, ante todo, como una comunidad de hombres, 0 sea que debe integrarse y regirse conforme a manera como se rigen, o deben regirse al menos, todas las demás comu. nidades humanas, siendo interesante recordar las atinadas consideraciones expuestas por Juan XXIII, no solo en su enciclica "Mater ef Magistra" sino, también, en la "Pacem in terris", algunos de cuyos conceptos han sido reafirmados por el actual Papa, Paulo VI, sobre la necesidad de una verdadera y real participación de los trabajadores "en los destinos de la Empresa".

También la participación de los trabajadores en la gestión de la empresa, puede ser considerada como una cuestión de sicología social, limitandome a señalar que, desde el punto de vista de las relaciones humanas, dentro de la empresa, estas se desarrollan, deben desarrolarse, dentro de un clima distinto, siendo necesário, además, que tanto los trabajadores como los empresarios capitalistas, se desprendan de una serie de "reacciones" sicológicas.

Por último, dentro del terreno moral, debo repetir lo ya sostenido en otras oportunidades, con respecto al problema moral de la empresa, es decir, que se trata, sobre todo de un "problema moral" o sea, de la necesaria transformación de las estructuras sociales, a las que, insisto, se ha referido recientemente el Papa Paulo VI, en su enciclica "Populorum Progressio", al decir que esta transformación solo puede operarse validamente dentro de una consiguiente transformación moral de los hombres que la integran, apoyandose en los principios rectores de Justicia Social y Caridad Amor cristianos.

La participación de los trabajadores en la gestión de la empresa, la cogestión lału sensu, puede decirse, tiene una série de ventajas,

33) Autor y obra cit. 
ya que quita el monopolio económico-técnico al capital factor pura mente instrumental -, y significa un reconocimiento del valor trabajo, instaurandose un clima de verdadera Paz y Justicia dentro de la Empresa. En cambio, mal entendida, puede producir un desorden en la dirección un verdadero conflicto de su autoridad, que ha hecho decir a algunos tratadistas, que, para evitarlos, debe reco nocerse, expresamente, a los portadores del capital: a) la unidad de mando b) la autoridad del jefe de la empresa, aunque dicho reconocimiento importaría, en realidad, una limitación esencial de la participación de los trabajadores en la gestión de la empresa.

3. ${ }^{\circ}$ Participación en la propiedad. Copropiedad.

La tercera categoría de la reforma "particionista" es la que se refiere a la propiedad de la empresa, a la propiedad de los bienes de producción.

Se trata aqui, como señala Valsecchi (34), de una reforma "integral" de la estructura de la empresa, y puede afirmarse que tanto la participación en los beneficios como la participación en la gestión, no son sinó propositos y medios para llegar al aceso de los trabajadores a la propiedad de la empresa, que es, o debe ser, al menos, el fin buscado.

Los procedimientos para llegar a la practica de la participación de los trabajadores en la propiedad de la empresa en que trabajan son múltiplas, pudiendo señalarse, entre ellos, los siguientes: a) la empresa dá facilidades a sus trabajadores para que adquieran, con sus ahorros, o con pequeños descuentos sobre sus remuneraciones, acciones comunes de la misma. Este sistema tiene muchos inconve. nientes, y cuando las remuneraciones son magras, es practicamente irrealizable. Además, a vezes, es utilizada para que los trabajadores sean privados de las vantajas y beneficios que les reconoce la actual legislación laboral, sosteniendose que los trabajadores "subordinados" se han transformado en "socios acionistas" de la empresa. b) la empresa dá a sus trabajadores una participación en los beneficios, por lo menos, en los extraordinários, en forma de acciones y/o colectivas. c) la empresa gratuitamente, entrega, acciones a los trabajadores que reunem determinadas condiciones, normalmente, al cumplir determinados años de servicio. d) las organizaciones sindicales adquieren acciones en el mercado de valores con la cotización de sus afilia. dos, para poder participar en las juntas generales de accionistas, en igualdad de condiciones que los demás integrantes de la sociedad, pudiendo así, influir, en las decisiones de la misma. e) el estado

34) Autor y obra cit. pg. 514. 
expropia determinadas empresas, y las entrega, para su explotación a grupos de trabajadores, y/o a una organización sindical, que abona en cuotas el precio, extravandolo de sus mismos benefícios.

Puede decirse que las formas expresadas en los puntos b) y c) son, en realidad, maneras especializadas de participación de los trabajadores en la propiedad de la empresa, formas especializadas que son conocidas, tanto en la doctrina como en la legislación, bajo la denominación de "accionariado obrero", y usadas, anque en forma voluntaria en distintos paises sobre todo en Inglaterra, habiendose intentado su aplicación, sin mayor éxito, en la Republica Argentina, por empresas de capital britanico, hace años.

Los últimos Papas se han referido al problema en forma repetida, manifestando su deseo de que la propiedad de la empresa, incluso de los medios de producción, se vaya otorgando paulatinamente, a los trabajadores. Juan XXIII en su enciclica "Mater et Magistra", precisa este punto al señalar, textualmente: "hay muchos estados en que la estructura económica nacional permite realizar, no pocas veces, a las empresas de grande o de mediana proporciones, rapidas e ingentes aumentos de producción, a traves de la autoafirmación, que renueva y complementa su equipo industrial. Cuando esto ocurre, juzgamos puede establecerse que las empresas reconozcan, por sí mismas, razón a sus trabajadores, un titulo de credito, especialmente si se les paga una remuneración que excede la cifra del salario vital. Este deber de Justicia puede cumplirse de diversas maneras, como la experiencia lo demuestra. Una de ellas y más deseable, en la actualidad, consiste en hacer que los trabajadores, en la forma y grado que parezca más oportunamente puedan llegar a participar poco a poco, en la propiedad de la empresa donde trabajan".

El Papa Juan XXIII, entonces, no solo señaló, doctrinariamente. el deber de justicia de hacer participar paulatinamente a los trabajadores en la propiedad de la empresa en donde trabajan, sinó también, un metodo a seguir, como el más deseable y conveniente, en el momento actual.

Deseo señalar, también, que las ventajas de la participación en la propiedad de la empresa son aún mejores, si cabe, que las señaladas al referirme a la participación en los beneficios y en la gestión de la empresa.

Es claro, asimismo, debo señalar, que, de acuerdo a la experiencia extranjera, es decir, a las realizaciones efectuadas en varios países, sobre todo en Europa, la participación en la propiedad de la 
empresa ha sido resistida tanto por determinados sectores de traba. jadores, mejor sería decir, por determinados dirigentes sindicales, imbuidos del doctrinariado marxista leninista, sosteniendo que no se trata sino de un paliativo para evitar la lucha de clases $y$, en el fondo manteniendo las actuales estructuras económicas, y, también, por vastos sectores del capitalismo-liberal, que sostienen que dicha participación es violataria del principio de la propiedad privada de la empresa.

\section{I}

\section{CONCLUSIONES:}

Debo señalar, antes que nada, que la "nueva empresa" - "la empresa comunitaria", debe asentarse bajo el principio fundamental de que la empresa es, mejor dicho, debería ser, ante todo "una comunidad humana". Esta concepción humana de la empresa, permite señalar la existencia, dentro de la misma, de dos estructuras distintas: a) una estructura material, que es la unidad funcional de producción, constituida por el concurso de los tres factores: capital, dirección y trabajo, que integran el quehacer económico, y hacen de ella fuente de bienes y geradora de rentas; y b) una estructura personal y humana, y esa es la empresa "comunidad de trabajo".

Esta distinción comunitaria, precisa Urdanoz (35), entre empresa como "organización productora", con su estructura jerarquica; $Y$ como comunidad humana formada - integrada - por todos aquellos que, de una manera u otra, cooperan en ese proceso productivo, más no en cuanto a simples productoras, sinó como personas que forman - integran -, un grupo social, con exigencias de orden material, cultural y humano, constituye la "esencia" de la nueva concepción de la empresa.

También debe señalarse, que no pueden quedar reducidas esas "relaciones humanas", dentro de la empresa, como pretende la concepción liberal-individualista, en un conjunto completo de relaciones jurídicas interindividuales, relaciones entre un empresario-capitalista y cada uno de los trabajadores; sinó una forma de realidad social', constituida, precisamente, por una "comunidad de personas", siendo un hecho innegable que los trabajadores se sienten cada día más concientes de su dignidad humana y de su condición de sujetos de los derechos de la vida social, no resignandose a prestar la aportación de actividades meramente mecanicas, sinó que en el hombre, el hombre integral, con sus facultades superiores, sus propias iniciativas y su tendencia innata de solidariedad, el que 
aspira a integrarse en su vida, de trabajo, donde transcurre buena parte de su existencia.

La concepción comunitária implica una organización humana de la empresa, y una organización económica, verdaderamente humana no existirá sinó en la medida en que distribución de las competencias de decisión, respecte la autonomía de las personas y de los grupos sociales, que le han constituído libremente.

En esa comunidad - empresa, sigue señalando Urdanoz (35) los trabajadores han de sentirse solidarios en la realización de una obra en común; puesto que se les exige dedicación exclusiva, tan amplia en ese comun interes, no se les puede atribuir el papel de meros adheridos espectadores. En la estructura de la empresa, los poderes y obligaciones deben distribuirse entre todos los participantes de la obra en común.

La concepción de la empresa debe, sin duda alguna, salvaguardar el principio de autoridad y la necesaria eficacia de la unidad de dirección, pero sin violar estos dos principios debe establecerse un sistema que permite a los trabajadores "hacer: valer su experiencia", respecto a las decisiones de la empresa, que orientan su actividad.

La concepción "comunitária" de la empresa es, indudablemente la "concepción institucional de la empresa", la concepción humana y cristiana de la empresa, atreviendome a llarmarla la: "concepción democratica" de la empresa; concepción que parte del principio fundamental del respecto a los derechos esenciales de la persona humana, que consiente y favorece el desarrollo integral de la personalidad de todos y cada uno de sus integrantes. 